\title{
¿ES NECESARIA LA CERTIFICACIÓN ENERGÉTICA EN EL CASO DE AUTO-PROMOCIONES? LA EFICIENCIA ENERGÉTICA COMO "CUESTIÓN DE INTERÉS GENERAL?
}

\author{
Dr. Lorenzo Mellado Ruiz \\ Profesor Titular de Derecho Administrativo \\ Universidad de Almería
}

Artículo Recibido: 28/01/2015

Artículo Aceptado: 17/02/2015

I SUMARIO.

I. Las certificaciones de eficiencia energética de edificios no son meros instrumentos privados de información de los consumidores; II. Caracterización jurídica básica de la calificación/certificación de eficiencia energética; III. La "trascendencia pública" de la calificación de eficiencia energética de los edificios

\section{Las certificaciones de eficiencia energética de edificios no son meros instrumentos privados de información de los consumidores}

Derecho privado, y sus instrumentos de aplicación y control, a veces deparan sorpresas como la Resolución que vamos a comentar en este breve estudio, la Resolución de la Dirección General de los Registros y del Notariado de 2 de abril de 2013, que viene a ratificar la, a nuestro juicio obvia, funcionalidad jurídico-pública de los certificados de eficiencia y ahorro energéticos de los edificios en nuestro país. La progresiva implantación de una nueva "cultura del consumo energético eficiente" 4 exige pronunciamientos como el reseñado, confirmándose la trascendencia pública, de "interés general", de un instrumento transversal aun precariamente regulado, en cuanto a sus efectos imperativos, por nuestro ordenamiento jurídico.

Efectivamente, a pesar de que el consumo energético de los edificios, fundamentalmente en el sector residencial, supone aproximadamente un $17 \%$ del total en nuestro país, y un $25 \%$ en el caso concreto del consumo eléctrico ${ }^{45}$, la regulación estatal básica en materia de certificación de eficiencia energética sigue siendo un marco mínimo de ordenación de carácter fundamentalmente informativo y proyectado sobre las relaciones jurídico-privadas inmobiliarias.

El nuevo RD 235/2013, de 5 de abril, por el que se aprueba el procedimiento básico para la certificación de la eficiencia energética de los edificios, que ha venido a sustituir, ampliando no obstante su ámbito objetivo de aplicación, al anterior RD

${ }^{44}$ Vide BARRASA SHAW, J., "Real Decreto 235/2013, por el que se aprueba el procedimiento básico para la certificación de la eficiencia energética de los edificios", El Consultor de los Ayuntamientos y de los Juzgados, 9, (2013), pág. 899 y ss.

${ }^{45}$ Vide DEL MONTE DIEGO, J., "La expedición del certificado de eficiencia energética para los inmuebles según el Real Decreto 235/2013, de 5 de abril y la Ley 8/2013”, Práctica de Tribunales La Ley, 106, (2014). 


\section{WPS Review International on Sustainable Housing and Urban Renewal (RI-SHUR)}

47/2007, de 19 de enero, habilitando así la transposición de la nueva Directiva 2010/31/UE, relativa a la eficiencia energética de los edificios, sigue focalizando la viabilidad de este grupo normativo en la "promoción de la eficiencia energética" mediante la "información objetiva" que obligatoriamente habrá de proporcionarse a los compradores y usuarios de edificios -nuevos o antiguos- en relación con las características energéticas de los mismos, materializada en forma de un certificado de eficiencia energética que permita valorar y comparar sus prestaciones (art. 1.2). Se trata, por tanto, de fórmulas de ordenación indirecta del mercado inmobiliario. Falta por ello, posiblemente, una auténtica "valorización" intrínseca, desgajada de su operatividad transaccional, de la eficiencia energética de los edificios. Es evidente, no obstante, y como se ha destacado, que se trata de un instrumento importante de racionalización energética, pues valorando y comparando la eficiencia energética de los edificios -existentes o nuevos- se favorecerá mediatamente la promoción de edificios de alta eficiencia energética, las inversiones (privadas) en ahorro de energía en función de su posterior recuperación- y el conocimiento real del nivel de emisiones de $\mathrm{CO} 2$ por el uso de la energía proveniente de fuentes emisoras del sector residencial ${ }^{46}$. Pero la consecución armonizada de los objetivos comunitarios de ahorro energético posiblemente requiera de nuevas fórmulas de intervención pública más incisivas en orden a su garantía y consecución. $Y$ en este sentido, algunas Comunidades Autónomas, dentro de su capacidad de "desarrollo más restrictivo" de las previsiones básicas estatales, han venido a dotar a los certificados de eficiencia energética inmobiliaria de una cierta "funcionalidad" vinculante: junto a los efectos "informativos" propios del mismo, sustanciados en la obtención -previo cumplimiento de los requisitos necesarios- y exhibición o puesta a disposición de la "etiqueta de eficiencia energética", se exige en algunas normas autonómicas un "umbral mínimo" de calificación energética y, sobre todo, se subordina la concesión de las licencias de apertura o puesta en funcionamiento y ocupación a la correspondiente y previa obtención de dicha calificación de eficiencia energética positiva. El edificio que no alcance -en proyecto y, ulteriormente, tras su finalización- la calificación mínima reglamentariamente exigida no podrá disponer de Certificado Energético y, en consecuencia, no procederá la concesión de la oportuna licencia de primera ocupación o de puesta en funcionamiento ${ }^{47}$.

Lo que ponen de manifiesto estos "avances normativos" es la, a mi juicio obvia, naturaleza jurídico-pública de los sistemas de certificación de eficiencia energética. Porque el ahorro energético y la racionalización del consumo -con sus lógicas repercusiones de modulación de las necesidades de demanda y dependencia energética y de emisión de gases de efecto invernadero- no es sólo una "cuestión" privada, entre compradores y vendedores, ni siquiera un evidente "derecho subjetivo" de los consumidores al efectivo conocimiento de todas las características de la

${ }^{46}$ DOMINGO LÓPEZ, E., Ahorro y eficiencia energética en la edificación de Andalucía: marco normativo, en GARCÍA RUBIO, F. y MELLADO RUIZ, L. (dirs.), Eficiencia energética y Derecho, Dykinson, Madrid, 2013, pág. 30. Hay que tener en cuenta, además, que no se trata sólo de objetivos relativos: la nueva Directiva marco 31/2010/UE obliga a que, a 31 de diciembre de 2020, "todos" los edificios nuevos sean de "consumo de energía casi nulo" (y dos años antes los de titularidad pública).

47 Así, art. 25.3 de la Ley 2/2007, de 27 de marzo, de fomento de las energías renovables y del ahorro y eficiencia energética de Andalucía y su reciente Reglamento de desarrollo contenido en el Decreto 169/2011, de 31 de mayo. 


\section{WPS Review International on Sustainable Housing and Urban Renewal (RI-SHUR)}

vivienda a adquirir o alquilar, sino un "indicador" o "factor" de interés general", trascendente -como complemento- a los propios intereses privados, y vinculado hoy en día al principio general transversal de protección del medio ambiente dentro de nuestro entero ordenamiento jurídico.

Esa es la premisa central, y la propia conclusión, de la Resolución que comento: la exigencia de acreditación del certificado de eficiencia energética responde realmente a una exigencia específica de la política europea, y a su través estatal, en materia de protección del medio ambiente y de la política energética, y no sólo a exigencias normativas derivadas de la normativa, más estrecha lógicamente, de protección de los consumidores y usuarios. Puede decirse por ello que, aún en sede de construcción jurisprudencial, la calificación energética de los edificios y su certificación acreditativa no son meros instrumentos informativos o de fomento indirecto de la preservación de la "posición" privada de los consumidores, sino fórmulas generales de "protección ambiental", instrumentos de prevención del "interés general ecológico" sustanciado en la racionalización del consumo de los recursos energéticos. No sólo, ni quizás principalmente, se trata de promover edificios energéticamente eficientes e inversiones en ahorro de energía, sino de viabilizar la integración técnica de la variable medioambiental en la toma de decisiones (privadas y públicas), conectando con la actual configuración funcional del complejo concepto del desarrollo sostenible. Veamos cómo se llega a dicho resultado valorativo.

\section{Caracterización jurídica básica de la calificación/certificación de eficiencia energética}

Puede decirse que, en su regulación actual, los sistemas de calificación y posterior certificación (acreditación) de la eficiencia energética de los inmuebles (tanto privados como públicos) vienen respondiendo a las siguientes notas caracterizadoras:

- Se trata de instrumentos de acreditación relativa del consumo energético. La calificación energética vendría a ser el "diagnóstico" de las características y potencial de ahorro y eficiencia energética de los proyectos y de los edificios terminados, permitiendo o favoreciendo, ulteriormente, el ahorro energético a través de la implementación de acciones de mejora o del incremento de la eficiencia de los diversos factores que determinan, en definitiva, el consumo energético del edificio, vivienda o local. Pero no es una valoración del ahorro energético neto del inmueble. La certificación, así, se "apoya" en "modelos de referencia, que cumplen con los requisitos mínimos de salubridad, habitabilidad y eficiencia, y en función de un uso determinado. No se efectúa, así, una evaluación del valor absoluto de consumo energético, sino un estudio comparativo con un específico consumo ideal teórico ${ }^{48}$. Y además, estos denominados "documentos reconocidos" de referencia ni siquiera tienen carácter reglamentario, sino simplemente de "documento técnico", con positivización

${ }^{48}$ En este sentido, se manifiesta críticamente por ejemplo DEL MONTE DIEGO, J., "La expedición del certificado ...", op. cit. 


\section{WPS Review International on Sustainable Housing and Urban Renewal (RI-SHUR)}

meramente enunciativa o abierta (art. 3.1 RD 235/2013) ${ }^{49}$. Al final, el Derecho no sólo "conecta" con la técnica, sino que prácticamente se hace depender de ella;

- Es una fórmula de verificación de la eficiencia energética de responsabilidad privada, pero de elaboración técnica. Aunque ya no es un instrumento "voluntario" (en todos los supuestos) $)^{50}$, no puede decirse que sea un certificado oficial. Es el propietario o promotor el que tiene la obligación de poner a disposición de los compradores o usuarios de los edificios el certificado de eficiencia energética. Es, pues, un instrumento jurídico privado con determinados efectos jurídico-públicos ${ }^{51}$. Responde a los nuevos postulados de colaboración privada y autorregulación ambiental propios de los modelos avanzados de interconexión entre los sistemas de protección y gestión ambiental y la actividad coadyuvante del mercado o de los propios sujetos particulares en sus relaciones económicas o sociales ${ }^{52}$. Como acertadamente se ha señalado, cada vez se aprecian más sectores normativos donde se combinan, con normalidad, formas jurídico-privadas y formas jurídico-públicas de cumplimiento del Derecho. Más que ante episodios de "privatización" -desde la perspectiva del aseguramiento del cumplimiento de las normas correspondientes- asistimos realmente, en muchos casos, a la iuspublificación parcial de sectores hasta ahora reservados a la "tutela judicial" en caso de incumplimiento. Una "certificación" como la estudiada supone, en definitiva, la colaboración pública de la Administración en la garantía de la eficacia de la regulación:

${ }^{49}$ E incluso, como dice expresamente el art. 5.3 del RD 235/2013, de 5 de abril, la certificación de viviendas unifamiliares podrá basarse en la "evaluación de otro edificio representativo de diseño y tamaño similares, y con una eficiencia energética real similar", si el técnico competente que expide el certificado de eficiencia energética puede garantizar tal correspondencia. Es verdad que se trata de viviendas unifamiliares, no de edificios en alzada o de propiedad horizontal, pero realmente lo que se permite no es certificar la eficiencia energética, sino la "correspondencia" con otra vivienda "similar". Podrá certificarse la eficiencia energética directamente por comparación, sin necesidad ni siquiera de estudios técnicos in situ. La garantía reside, más bien, en la "profesionalidad" e "independencia técnica" el responsable técnico del análisis. Junto a ello, es evidente también -y a mi juicio con lógica justificación- en carácter limitado y sectorial de la certificación: "el certificado de eficiencia energética dará información exclusivamente sobre la eficiencia energética del edificio y no supondrá en ningún caso la acreditación del cumplimiento de ningún otro requisito exigible al edificio" (art. 5.4.).

${ }^{50}$ El nuevo RD 235/2013, de 5 de abril, modifica y amplia el ámbito objetivo de aplicación del anterior RD 47/2007, de 19 de enero, obligando a que todos los edificios o unidades de éstos, y no sólo los de nueva construcción, cuando se construyan, vendan o alquilen dispongan de un certificado de eficiencia energética. Pero la perspectiva normativa sigue siendo, en mi opinión, limitada. La norma sigue centrada en la funcionalidad "privada" de este instrumento, ancilar a las actividades de construcción o transacción inmobiliaria. Pervive aún, pues, la perspectiva de la protección de los adquirentes, consumidores o usuarios, y no la de la preservación del "ambiente" general, como "valor jurídico" de todos los ciudadanos, en su "evidente" afección por la falta de eficiencia, el derroche y el limitado control del consumo energético de nuestro parque inmobiliario.

51 Esta dimensión jurídico-pública se ha visto reforzada, evidentemente, a través de la vinculación definitiva del contenido prescriptivo de las determinaciones reglamentarias indicadas con las consecuencias (necesariamente legales) reactivas en caso de incumplimiento, mediante la inclusión “internormativa", podría decirse- del régimen de sanciones correspondiente en la posterior Ley 8/2013, de 26 de junio, de rehabilitación, regeneración y renovación urbanas. Se establece en ella, concretamente, que tanto publicitar como vender o alquilar un edificio o parte del mismo sin el correspondiente certificado debidamente registrado constituye una infracción muy grave o grave, respectivamente.

${ }^{52}$ Pueden estudiarse estos nuevos enfoques de colaboración público-privada en el estudio general de PERETZ, N., "Growing the energy efficiency market through third-party financing", Energy Law Journal, 30, (2009), pág. 377 y ss., con especial atención a la dimensión complementaria económica de la colaboración, es decir, a la propia "recuperación" privada de la inversión en eficiencia energética a través del retorno en las ventas de los edificios. 


\section{WPS Review International on Sustainable Housing and Urban Renewal (RI-SHUR)}

la "summa divisio" parece ser hoy más un "binomio de cualidades que de entidades"53. Ahora bien, la responsabilidad jurídica se desvincula en cierta forma de la responsabilidad técnica: el promotor o propietario del edificio o una parte del mismo (un local independiente, por ejemplo) es el responsable de "encargar" la realización de la certificación de eficiencia energética, y, ahora también, de su inscripción en el Registro administrativo autonómico correspondiente ${ }^{54}$; pero su realización compete, obviamente, al técnico correspondiente. Dice así el art. 8 del RD 235/2013, que "el certificado será suscrito por técnico competente, que será elegido libremente por la propiedad de edificio", debiéndose entender por tal cualquier técnico que esté en posesión de cualquiera de las titulaciones académicas y profesionales habilitantes para la redacción de proyectos o dirección de obras y dirección de ejecución de obras de edificación o para la realización de proyectos de sus instalaciones térmicas, según lo establecido en la Ley 38/1999, de 5 de noviembre, de Ordenación de la Edificación (LOE), o para la suscripción de certificados de eficiencia energética, o haya acreditado la cualificación profesional necesaria para suscribir certificados de eficiencia energética, en virtud de la habilitación establecida en la D. A. 4⿳亠丷a de la norma. La fórmula de colaboración técnica es, pues, amplia y flexible, admitiéndose tanto profesionales y técnicos titulados como "profesionales cualificados" 55 . Pero, en cualquier caso, se trata de un procedimiento técnico de análisis de naturaleza privada, aunque con indudables efectos públicos aparejados. Por eso, entre otros aspectos, la normativa vigente impone a las Comunidades Autónomas que establezcan "sistemas de control independientes" para verificar la validez, complitud e idoneidad de los certificados de eficiencia energética emitidos (art. 9 del RD 235/2013) ${ }^{56}$, aparte de los clásicos mecanismos, siempre necesarios, de inspección y seguimiento ${ }^{57}$;

\footnotetext{
53 Vide VELASCO CABALlERO, F., Derecho público más Derecho privado, Marcial Pons, Madrid, 2014, pág. 18-19.

${ }^{54}$ Así se desarrolla, por ejemplo, en el reciente Decreto 46/2014, de 1 de abril, por el que se regulan las actuaciones en materia de certificación de eficiencia energética de edificios y crea su registro, en el ámbito de la Comunidad Autónoma de Aragón. Como se dice en el mismo, la obligatoriedad de inscripción exigida por el nuevo art. 5.6 del RD 235/2013, de 5 de abril, pretende afianzar la confianza del consumidor en la toma de decisiones de compra o alquiler, pero también que la Administración disponga de la información necesaria para la comprobación, estudio, seguimiento y control de las ratios de eficiencia energética del sector. El Registro es, de hecho, un Registro público de naturaleza administrativa, poniéndose también de manifiesto, desde esta complementariedad funcional de la actividad pública de constancia, la reseñada trascendencia jurídico-pública de la certificación de eficiencia energética de los edificios.

${ }^{55}$ Bien es verdad, no obstante, que, como mecanismo de prevención, la propia D. A. $4^{\text {a }}$ del RD 235/2013, de 5 de abril, remite a una futura Orden para la efectiva determinación de dichas "cualificaciones profesionales", requeridas para la suscripción de los certificados de eficiencia energética, así como los medios para su acreditación formal, y debiéndose tener en cuenta, en todo caso, "la titulación, la formación, la experiencia y la complejidad del proceso de certificación”. Dicha Orden aún no ha sido publicada, por lo que sigue en el aire la cuestión de quiénes pueden ser "técnicos cualificados" (al margen de los titulados oficiales) competentes para la suscripción facultativa de estudios y proyectos de eficiencia energética. Algunas Comunidades Autónomas han establecido, como medida de seguridad jurídica, la posibilidad de que en el registro público de certificados también se puedan inscribir, voluntariamente, los técnicos competentes y las empresas que ofrezcan servicios de certificación; pero se trata de una posibilidad con efectos meramente informativos o publicitarios, y no limitativos de su encargo a cualquier otro técnico "competente".

${ }^{56}$ Control independiente que, por cierto, rápidamente se desvanece y evapora en el caso de los edificios públicos, donde se permite que la certificación de eficiencia energética, su control independiente
} 


\section{WPS Review International on Sustainable Housing and Urban Renewal (RI-SHUR)}

- La certificación de eficiencia energética no es un mero análisis formal de la adecuación "técnica" del edificio. Materialmente, el certificado de eficiencia energética debe incluir "información objetiva" sobre la eficiencia energética del edificio, y los valores de referencia utilizados. No se trata de un mero instrumento preventivo de control formal de la adecuación funcional del edificio a los requerimientos técnicos exigidos por la normativa correspondiente (en concreto, a los "requisitos mínimos de eficiencia energética" contenidos en el Código Técnico de la Edificación, aprobado a través del RD 314/2006, de 17 de marzo). La certificación energética, en su propia funcionalidad informativa y promocional, deber tener un "valor adicional", acreditando la "viabilidad energética" del edificio para los potenciales adquirentes o usuarios. Como se desarrolla en el art. 6 del RD 235/2013, el contenido del certificado de eficiencia energética no se condensa en la mera identificación del edificio y de los procedimientos utilizados y en la descripción de las características energéticas del mismo y su "calificación" semiótica de eficiencia correspondiente, sino que, para los edificios existentes, deberá contener un documento de recomendaciones para la mejora de los niveles óptimos o rentables de eficiencia energética, a menos que no exista ningún potencial razonable para una mejora de esa índole en comparación con los requisitos de eficiencia energética vigentes.

\section{La "trascendencia pública" de la calificación de eficiencia energética de los edificios}

A pesar de los avances (en su obligatoriedad, ámbito objetivo de aplicación, régimen sancionador aparejado, etc.), lo cierto es que, en principio, las certificaciones energéticas de los inmuebles parecen seguir incluyéndose, fundamentalmente, dentro de los instrumentos privados de mercado. Son análisis técnicos privados, obligatorios, pero no orientados a la "valorización energética" general (absoluta o genérica) del parque inmobiliario -en el caso de los edificios ya existentes-, sino más bien a la protección de los consumidores, usuarios y compradores desde la perspectiva de la correcta información de las características de los edificios a los efectos de su comparación. Bien es verdad que, como cualquier fórmula de intervención económica indirecta ambiental, se supone que, mediatamente, esta "mejor información" repercutirá favorablemente en la "libertad de elección", y, en el fondo, en la opción -y progresiva generalización- por edificios y viviendas energéticamente eficientes. Pero no dejan de ser instrumentos informativos, de carácter declarativo y técnico.

Tampoco se trataría, sin embargo, en momentos de "deconstrucción" de la acción pública interventora directa a nivel comunitario, de convertirlos en mecanismos públicos de evaluación preventiva formal y autorización vinculante (con sus posibles

(sic!) y la inspección la realicen "los técnicos competentes de sus propios servicios internos" (D. A. $1^{\mathrm{a}}$ del RD 235/2013, de 5 de abril).

57 A pesar de ello, y como se ha destacado, contrasta la amplia funcionalidad "pública" de una valoración de eficiencia energética puramente privada, en sintonía con la ya reseñada prevalente naturaleza privada de estos instrumentos, con otros modelos de una mayor intervención pública administrativa sobre proyectos reservados de hecho a profesionales titulados, en algunos casos con colegiación obligatoria $\mathrm{y}$, en otros, con visado colegial adicional, vide VELASCO CABALLERO, F., "Sujetos privados en las comunicaciones previas y las declaraciones responsables para el control municipal de actividades económicas”, Revista Española de Derecho Administrativo, 165, (2014), pág. 37. 


\section{WPS Review International on Sustainable Housing and Urban Renewal (RI-SHUR)}

costes asociados, tanto de carácter burocrático como económico). Pero, sin dejar de ser fórmulas informativas de estímulo o fomento, sí podrían dotarse de una mayor "cualificación" pública, por ejemplo, y como se ha reseñado, mediante la exigencia de un "mínimo de calificación energética", junto con su vinculación funcional a la necesaria licencia de obras, primera ocupación o puesta en funcionamiento del edificio o unidad del mismo ${ }^{58}$, o la obligatoriedad de incluir en los certificados -junto al diagnóstico técnico- una serie de medidas necesarias para ascender -progresiva 0 directamente- uno o más grados en la escala de eficiencia.

Porque no se trata sólo de gestionar el consumo (privado) de energía, sino de ordenar, al menos a la vez, el ahorro (público) de los recursos. La "eficiencia energética" de los edificios no es una cuestión meramente privada, de las relaciones jurídicas patrimoniales con bienes inmuebles. También es un indicador basilar de los objetivos y principios generales jurídico-públicos de ordenación del modelo energético, tanto a nivel interno como supraestatal. Así se sostiene en la Resolución de 2 de abril de 2013 que paso a desglosar.

El interrogante fáctico de partida es la duda sobre la necesidad o no de aportar la certificación de eficiencia energética en el caso de autopromociones inmobiliarias. Si se trata de un instrumento meramente informativo y de mercado, en principio no sería exigible en el caso de la autopromoción privada de una vivienda, sin ánimo de venta o alquiler. Pero, si la vivienda no se va a vender o a alquilar, ¿no parece razonable realizar una evaluación de su eficiencia energética de igual manera? ¿Cuál es el objetivo de este instrumento entonces, sólo "promover" indirectamente la construcción o el mantenimiento de edificios de alta eficiencia energética o posibilitar/coadyuvar el cumplimiento -o la autorresponsabilización- de los objetivos y exigencias generales de ahorro, contención y sostenibilidad energética? ¿Cuál es el fin de las Directivas comunitarias en este punto, sólo otorgar derechos subjetivos de contenido patrimonial e informativo a los usuarios de inmuebles o a futuros compradores sobre las características energéticas de los inmuebles con carácter previo a su adquisición o, en el marco de las políticas energéticas y económicas generales de la Unión, postular una progresiva implementación complementaria de los deberes genéricos de acreditación de un mínimo de eficiencia energética en los edificios? ¿La eficiencia energética es un "criterio más de compra o alquiler" o es una necesidad/obligación pública proyectada o redistribuida en el escenario específico de las relaciones inmobiliarias patrimoniales?

${ }^{58}$ El Reglamento andaluz 169/2011, de 31 de mayo, establece, en este sentido, la específica obligación de que todos los edificios incluidos en su ámbito de aplicación deban alcanzar, como mínimo, una calificación de eficiencia energética " $\mathrm{D}$ ” y que no podrá concederse la licencia de primera ocupación o de puesta en funcionamiento sin contar, previamente, con el correspondiente $-\mathrm{y}$ positivo, obviamenteCertificado de eficiencia energética. Es verdad que el tenor literal no se refiere expresamente a la imposibilidad de obtener la "licencia de obras" del edificio, pero carece de sentido exigir una "calificación energética mínima" a los edificios construidos y no a los proyectos de edificios, donde es más factible la implementación de las acciones, mejoras y exigencias derivadas o impuestas por la misma. De lo contrario, de ejecutarse la obra conforme a un proyecto que no alcance dicha calificación mínima, el edificio realmente nunca llegaría a ocuparse o ponerse en funcionamiento por incumplir la calificación de eficiencia energética mínima exigida. Así se ha interpretado el art. 16.6 del Reglamento, que establece que "ningún edificio o unidad de uso cuya calificación sea menor a la categoría «D» podrá ser construido, ocupado o puesto en funcionamiento". 


\section{WPS Review International on Sustainable Housing and Urban Renewal (RI-SHUR)}

A mi juicio, es evidente la doble naturaleza, pública y privada, de los certificados de eficiencia energética ${ }^{59}$.

La denegación de la inscripción registral de la correspondiente acta de declaración de fin de obra se basa, como punto de partida, en el incumplimiento de las exigencias impuestas por el art. 20 del RD Legislativo 2/2008, de 20 de junio, por el que se aprueba el Texto Refundido de la Ley del Suelo (TRLS). Como mecanismo de control de ajustamiento a la legalidad, impone este precepto con carácter básico que la autorización notarial de escrituras de declaración de obra nueva terminada se subordinará, además de a la certificación expedida por técnico competente acreditativa de la finalización de la obra conforme a la descripción del proyecto, al "otorgamiento de las autorizaciones administrativas necesarias para garantizar que la edificación reúne las condiciones necesarias para su destino al uso previsto en la ordenación urbanística aplicable y los requisitos de eficiencia energética tal y como se demandan por la normativa vigente, salvo que la legislación urbanística sujetase tales actuaciones a un régimen de comunicación previa o declaración responsable". Y el apartado segundo de este art. 20 confirma el carácter preceptivo de tales previsiones: "para practicar las correspondientes inscripciones de las escrituras de declaración de obra nueva, los Registradores de la Propiedad exigirán el cumplimiento de los requisitos establecidos en el apartado anterior". La redacción actual de este precepto trae causa de la modificación efectuada en tal sentido por el RD-Ley 8/2011, de 1 de julio, de medidas de apoyo a los deudores hipotecarios, de control del gasto público y cancelación de deudas con empresas y autónomos contraídas por las entidades locales, de fomento de la actividad empresarial e impulso de la rehabilitación y de simplificación administrativa, modificación normativa que es de aplicación a todas las escrituras o actas de obra nueva terminada otorgadas a partir del 7 de julio de 2011 a las que fuera de aplicación el RD 47/2007, de 19 de enero.

La imperatividad y el reforzamiento normativo en el control del cumplimiento de estas determinaciones se ponen de manifiesto en el doble control (notarial y registral) reseñado.

En el recurso contra la denegación de la inscripción registral se alegaba, en primer término, que tanto el citado Reglamento como su posterior sustituto, el RD 235/2013, de 5 de abril, no regulaban realmente ni exigían, como fórmulas de control preventivo autónomo, autorizaciones administrativas concretas, sino más bien los procedimientos básicos necesarios para efectuar la certificación de eficiencia energética de los edificios, a los efectos no tanto de controlar el ajustamiento material a la legalidad (urbanística y de edificación) sino de promocionar dicha eficiencia mediante una información completa y útil a los consumidores que les permitiera comparar ofertas y elegir. Además, se aducía la doctrina de la Dirección General de los Registros y del Notariado referida al ámbito subjetivo de tutela de las obligaciones impuestas a los promotores: cuando el objetivo no es proteger el interés del promotor sino el de ulteriores usuarios (adquirentes o consumidores), carecería de sentido imponer, con carácter preventivo y formal, el control de la documentación correspondiente. Y finalmente también se alegaba que la certificación exigida debía incorporarse al Libro

${ }^{59}$ Así lo afirma, por ejemplo, BAIRATI, L., La intervención de las Comunidades Autónomas y de las Regiones italianas en la transposición de las Directivas europeas. El caso de la certificación energética de los edificios, Institut d'Estudis Autonòmics, Barcelona 2012, pág. 18. 


\section{WPS Review International on Sustainable Housing and Urban Renewal (RI-SHUR)}

del Edificio, por lo que parecería lógico que la exigencia de acreditación del certificado de eficiencia energética se limitara a los mismos supuestos en los que se exige la justificación del mismo. En definitiva, se argumentaba que el certificado de eficiencia energética, aún exigido por la normativa, era fundamentalmente un instrumento privado de información conectado con los derechos subjetivos patrimoniales de los consumidores y usuarios más que con la protección, difusa y colectiva, de los intereses públicos ambientales.

La Dirección General de los Registros y del Notario se plantea, entonces, si esta exigencia del art. 20 TRLS se dirige realmente sólo a proteger a terceros, en cuyo caso no sería exigible en aquellos supuestos de autopromoción para uso propio. Y extrae de la normativa de fundamento, fundamentalmente el marco comunitario de referencia, esta primera conclusión: "la eficiencia energética es un atributo exigible a toda edificación nueva, siendo indiferente el uso a que se destine la misma (salvo excepciones y exclusiones específicas), teniendo por finalidad la promoción de que todos los edificios dispongan de unas características mínimas en el uso de la energía como objetivo de política urbanística y de edificación"60.

Es decir, que los objetivos de eficiencia energética son transversales y comunes a cualesquiera ámbitos y destinos edificatorios. El uso privado también puede ser -o derivar en- un uso energéticamente ineficiente. Las exigencias comunitarias se fundamentan y persiguen objetivos genéricos, comunes y uniformes, imponiendo la interpretación funcional y útil de las mismas una aplicación restrictiva tanto de las excepciones como de las modulaciones a su consecución por los Estados miembros. No sólo se persigue, pues, la protección "privada" de los intereses de consumo de los terceros adquirentes o usuarios, sino que se trata de un marco regulatorio "trascendente" al mero interés particular, orientado a la garantía general de la disponibilidad de umbrales mínimos de eficiencia energética por cualquier tipo de nueva edificación, sea cual sea el uso, destino u origen de la misma. Por ello se sostiene que se trata de previsiones de "protección ambiental y ordenación de la política energética", y no simples medidas de protección de los consumidores -aunque también lo sean-.

En este sentido, resulta destacable que tras la Ley 8/2013, de 26 de junio de Rehabilitación, Regeneración y Renovación urbanas, la certificación de eficiencia energética deba incluirse como parte del denominado "Informe de Evaluación de los Edificios" (art. 4.2.c), cuyo objetivo es asegurar la calidad y sostenibilidad del parque edificado, aparte de poder obtener los propios poderes públicos información precisa a los efectos de la orientación e implantación de sus acciones políticas. Debe acreditarse en el mismo el cumplimiento de tres grandes extremos: estado (y deber) de conservación del edificio; accesibilidad universal; y grado de eficiencia energética (integra, así, el contenido de la ITE y la certificación de eficiencia energética regulada en el ámbito comunitario, como un instrumento de defensa de los adquirentes y usuarios de viviendas). Es patente que no nos encontramos, por tanto, ante un mero

\footnotetext{
${ }^{60}$ Un comentario de esta Resolución puede encontrarse en la nota de SUNYER MARTÍN, Ma. M., ":Puede exigir el Registrador entre la documentación presentada para la inscripción de una obra nueva terminada, la certificación energética del edificio en un supuesto de autopromoción para uso propio?", en www. lasclavesdelderecho.com
} 


\section{WPS Review International on Sustainable Housing and Urban Renewal (RI-SHUR)}

instrumento informativo de naturaleza privada, sino ante un mecanismo acreditativo del cumplimiento de deberes y determinaciones públicas o cuasipúblicas, y, en cualquier caso, atinentes a los propios propietarios o titulares de los inmuebles, y no sólo en función de la proyección de los mismos en la protección de derechos de terceros. Parece claro, así, que se trata de un claro ejemplo de "iuspublificación mínima" de un sector en principio "privado-patrimonial" con fines de aseguramiento o garantía de la eficacia de las determinaciones normativas -y sus principios subyacentes-. En virtud de esta dualidad o combinación funcional, algún autor se ha cuestionado, a mi juicio con acierto, sobre la posibilidad de poder incluir y conexionar el deber de conservación de los edificios (art. 9.1 TRLS) con la exigencia de mejoras de las tasas de eficiencia energética correspondientes ${ }^{61}$.

Las distintas exigencias -sigue argumentando la Resolución- de acreditación del art. 20 TRLS, ya pertenezcan al orden urbanístico, al de protección de los consumidores o al desarrollo de políticas de protección del medio ambiente y eficiencia energética, responden en definitiva a distintas causas y motivaciones y su regulación material es diferente, por lo que sólo el análisis individualizado de cada uno de ellos permite determinar en qué casos y bajo qué condiciones puede "modalizarse" su aplicación. Por ello, dado que la exigencia de acreditación del certificado de eficiencia energética responde a una exigencia concreta y específica de la política de la Unión Europea en materia de protección del medio ambiente y política energética es de aplicación a toda edificación terminada dentro de su ámbito material y temporal. No se pretende sólo proteger los derechos a la información y patrimoniales de posteriores usuarios -lo que podría justificar la exención de algunos requisitos de control preventivo-, ni siquiera el interés del promotor, sino garantizar la eficacia de la regulación -comunitaria e internasobre ahorro y eficiencia energética en las edificaciones y viviendas.

Y se concluye: "Es cierto, como dice el recurrente, que el art. 7.5 del RD 47/2007, de 19 de enero, por el que se aprueba el Procedimiento básico para la certificación de eficiencia energética de edificios de nueva construcción, afirma que el certificado debe acompañarse al libro del edificio, pudiendo resultar perturbador cuando la acreditación de la existencia de éste no sea exigible. Pero establecido que la causa de exención alegada en la exigencia del libro del edificio (autopromoción para uso propio) no es de aplicación a la exigencia del certificado de eficiencia energética, es forzoso concluir que no puede impedirla, circunstancia por otro lado que no supone una carga adicional dado que el certificado debe ser expedido en cualquier caso de obra nueva construida, es suscrito por la dirección facultativa como una más de sus obligaciones y es objeto de entrega al propietario, quien tiene la obligación de conservarlo y renovarlo en su día".

Así pues, la normativa actual sobre acreditación de la eficiencia energética de los edificios no es una mera reglamentación procedimental del análisis técnico de la misma $^{62}$. Incluye, además, auténticos deberes jurídicos, vinculados al propio marco

\footnotetext{
${ }^{61}$ Vide MENÉNDEZ REXACH, Á., "El Informe de Evaluación de los Edificios en la Ley 8/2013”, Ciudad y Territorio. Estudios Territoriales, 179, (2014), pág. 63 y ss.

${ }^{62}$ Como se ha dicho, se trata de una reglamentación que "claramente desborda lo meramente técnico", y cuyo correcto seguimiento dará lugar a que se cuente con nuevos motivos basados en su eventual incumplimiento para incoar expedientes de protección de la legalidad urbanística, vide RUIZ ROMERO, F. A., "La certificación de eficiencia energética de edificios de nueva construcción y el
} 


\section{WPS Review International on Sustainable Housing and Urban Renewal (RI-SHUR)}

regulatorio comunitario de referencia. El art. 1 del nuevo RD 235/2013, de 5 de abril, como parte indudable de sus determinaciones normativo-prescriptivas (es decir, fuera de lo que sería más interpretable ${ }^{63}$, en cuanto a su "funcionalidad normativa", el "procedimiento básico para la certificación de la eficiencia energética de los edificios»), señala que "cuando se construyan, vendan o alquilen edificios o unidades de éstos, el certificado de eficiencia energética o una copia de éste se deberá mostrar al comprador o nuevo arrendatario potencial y se entregará al comprador o nuevo arrendatario". No se distingue, así, según los usos, destinos o forma de promoción de los edificios. Su nuevo ámbito objetivo de aplicación abarca, de un lado, "todos" los edificios de nueva construcción, y, de otro, los "edificios o partes de edificios existentes que se vendan o alquilen a un nuevo arrendatario, siempre que no dispongan de un certificado (previo) en vigor". Es evidente su funcionalidad informativa y de garantía de los derechos de terceros (mediante la muestra previa y la puesta a disposición de los adquirentes posterior), pero también sólo cuando se "construyan" (y no sólo cuando se vendan o alquilen), parece obligatorio contar con el certificado. Si no fuera así no tendría sentido la diferenciación "verbal" del precepto. La eficacia y el efecto útil del Derecho comunitario, y la propia "trascendencia" de los intereses públicos implicados, conlleva, pues, el reforzamiento de las garantías internas de acreditación de la eficiencia energética de los edificios. No hay, pues, una auténtica publificación material de esta regulación, pero sí una adición de fórmulas atenuadas de acreditación fundamentada en la garantía de la eficacia del propio grupo normativo.

Por todo ello puede afirmarse, a la vista de ejemplos aplicativos como esta Resolución, que no nos encontramos ante meros instrumentos privados informativos, de tutela subjetivo-patrimonial, de los derechos e intereses de los terceros (consumidores y usuarios), sino ante una técnica dual de protección conjunta de intereses privados y públicos, donde la Administración interviene -aún con instrumentos de mera certificación y control- para asegurar el cumplimiento efectivo de los objetivos generales de la normativa de cobertura: la certificación de eficiencia energética es, pues, una obligación genérica, incrustada ya claramente dentro del marco regulador de las políticas comunitarias e internas de protección del medio ambiente, ordenación de los sectores energéticos y protección/conservación de los edificios. Puede decirse que la norma "confía y se remite" en gran medida al "análisis técnico", pero no se "rinde" al mismo. La superación de las instancias públicas de decisión, democráticamente legitimadas, por parte de la complejidad técnica no supone, sin embargo, una elusión total de la protección de los "intereses generales" involucrados, aún de manera mediata o tangencial. No hay una completa sustitución, así, de los espacios de decisión por técnicas de autorregulación privada. La tutela ambiental y la sostenibilidad energética permiten trascender la mera operatividad privada de las técnicas de certificación, adicionando a su funcionalidad informativa una cierta

Código Técnico de la Edificación: su conexión con las licencias de obras y la protección de la legalidad urbanística", Práctica Urbanística La Ley, núm. Especial Mayo 2007.

63 Aún así, es evidente que no se trata de puras normas técnicas o programáticas. Como dice el art. 18 del RD 235/2013, el incumplimiento de los preceptos contenidos en el "procedimiento básico" se considerará en todo caso como "infracción" en materia de certificación de la eficiencia energética de los edificios, y se "sancionará" de acuerdo con lo dispuesto en las normas de rango legal que resulten de aplicación. 


\section{WPS Review International on Sustainable \\ Housing and Urban Renewal (RI-SHUR)}

garantía de la eficacia de sus objetivos últimos. El "mercado de las certezas" ${ }^{64}$-dentro de la necesaria recomposición actual de las relaciones entre la técnica y el Derechoha de compatibilizarse, en definitiva, con el respeto de los principios, valores y objetivos superiores informadores de cada sector o ámbito de normación, regulación o gestión jurídico-pública.

${ }^{64}$ ESTEVE PARDO, J., El desconcierto del Leviatán. Política y derecho ante las incertidumbres de la ciencia, Marcial Pons, Madrid, 2009, pág. 139. 